\title{
Relative importance of college success predictors: fluid intelligence, crystallized intelligence, and grit
}

\section{Mete, Ipek ${ }^{a}$ and Toker, Yonca ${ }^{b}$}

${ }^{\mathrm{a}}$ Department of Management, Ankara Yildirim Beyazit University, Turkey, ${ }^{\mathrm{b}}$ Department of Psychology, Middle East Technical University, Turkey.

\begin{abstract}
This study aimed to compare the predictive power of grit and two cognitive ability tests of fluid and crystallized intelligence used for university admission on the success of college students in Turkey. Utilizing Cattell's Investment Theory and Ackerman's PPIK Theory of Adult Intelligence, we hypothesized that knowledge tests would be a better predictor of academic achievement in college than tests of fluid intelligence. We collected data from 441 students enrolled in engineering, physical sciences, social sciences, and administrative sciences majors in a technical university. Our results based on hierarchical regression and dominance analyses provided support for our hypothesis. For science, technology, engineering and math (STEM) students, the test of crystallized intelligence not only was a better predictor of college GPA compared to the test of fluid intelligence but also explained incremental variance over and above the fluid intelligence test. For social-administrative sciences, the predictive powers of tests were equivalent to each other. We also found that the perseverance of effort dimension of grit was the best predictor of GPA. Our findings support the notions of the adult intelligence theories suggesting that domain knowledge is a better predictor of typical performance in adults.
\end{abstract}

Keywords: fluid intelligence; crystallized intelligence; knowledge test; academic success; grit; investment theory. 


\section{Introduction}

Cognitive ability has been shown as a successful predictor of school and academic performance (e.g., Kuncel \& Hezlett, 2007; Sackett et al., 2008). Nevertheless the predictive power of cognitive abilities tends to decline over the years from elementary school to college and graduate education (Kaufman, Johnson, \& Liu, 2008; Lin \& Humphreys, 1977; Postlethwaite, 2011). Cattell's (1987) Investment Theory forms the basis for emphasizing that adults invest their general reasoning abilities, that is fluid intelligenceGf, into areas they are interested in and thus acquire knowledge that makes up another type of cognitive functioning known as crystallized intelligence (Gc) and that Gc and Gf are differentially related to academic success.

Ackerman's (1996) theory of intelligence-as-Process, Personality, Interests, and intelligence-as-Knowledge (PPIK) frames intelligence-as-knowledge as a more specialized form of accumulated knowledge (i.e., occupational or discipline-related) as compared to Gc, which develops from intelligence-as-process and also motivational resources such as vocational interests and domain-related personality proclivities. Ackerman suggested that assessments of intelligence-as-knowledge should incorporate separate measures for each occupational/discipline-related domains. Empirical research provide support for these theories, suggesting that in high school and adult samples, knowledge-based assessments have better predictive power as compared to process-oriented intelligence assessments. Such results are in line with the findings indicating that previous performance and achievement levels are indicators of future achievements (Oullette \& Wood, 1998). In educational selection, researchers (e.g., Ackerman \& Beier, 2006; Rolfhus \& Ackerman, 1999) suggest that higher weight should be given to knowledge measures rather than ability measures. Knowledge measures (e.g., grade point averages) are indicators of typical performance whereas ability measures represent maximal performance. Furthermore, Gc is a better predictor of domain knowledge than Gf. For example, in a recent meta-analysis (Postlethwaite, 2011), undergraduate GPA was better predicted by Gc $(r=.36, \rho=.65)$, compared to Gf $(r=.22, \rho=.44)$.

Studies that focused on the predictive power of prior knowledge on undergraduate achievement showed consistent results. A meta-analysis (Richardson et al., 2012) reported a moderate effect size of high school GPA on undergraduate GPA $(\rho=.41)$. High school GPA explained $21.4 \%$ of variance in first year college achievement of American students whereas SAT scores explained only $2.4 \%$ of the variance (Fu, 2012). Similarly, in a study conducted in Sweden, high school GPA was a better predictor of graduate GPA than the scores on SweSAT, an exam used for college admissions with content similar to that of the SAT in the United States (Cliffordson, 2008). In a German sample, Gf accounted for 5\% of the variance in undergraduate GPA, whereas high school GPA and scores on knowledge tests added 22\% incremental variance (Kunina et al., 2007). Recently, Ackerman and 
colleagues (2013) found that the correlation of first-year undergraduate GPA with Advanced Placement exam scores, which assessed crystallized domain knowledge, was somewhat larger $(r=.38)$ as compared to its correlation with SAT scores $(r=.30)$. SAT-I, which is more heavily loaded with questions assessing fluid intelligence, was reported to add close to zero variance in predicting freshman GPA over and above the variance explained by high-school GPA and SAT-II (subject tests). Whereas the subject tests accounted for $22.3 \%$ of the variance (Geiser \& Studley, 2002).

Similar results pertaining to the relative differentiation of knowledge-based versus abilitybased measures of cognitive functioning have been reported in predicting graduate school success (e.g., Kilmen, 2007; Kuncel et al., 2001) and job success (e.g., Koczwara et al., 2012). In line with the literature, in the present study we sought to investigate the predictive power of two tests used in the university entrance system in Turkey: YGS-a measure of intelligence-as-process- and LYS-a measure of intelligence-as-knowledge. We hypothesized that LYS would be a better predictor of undergraduate CGPA than YGS. We tested our hypothesis separately using two clusters of students based on their field of major (STEM and Social Sciences) because the content of LYS test for university admission is different for these clusters. More information on the tests is provided in the methods section. In the analyses, we also included grit as predictor of GPA because of previously reported associations with academic success (Duckworth et al., 2007; Duckworth \& Quinn, 2009).

\section{Method}

\subsection{Participants and Procedure}

The sample included students at a technical university in Ankara. Upon obtaining IRB approval and participant consent, those who completed our online survey were offered course credit. Students who took the university placement exams (YGS and LYS) after 2010 were eligible for participation. The final sample after data cleaning included 441 students, with 231 enrolled in STEM majors and 210 enrolled in the social/administrative sciences. Sample characteristics for both clusters are reported in Table 1.

\subsection{Measures}

Participants manually entered their LYS and YGS exam scores. A link that directed the students to the score inquiry webpage was provided so that the students could provide objective and accurate scores. The YGS test is equivalent to a reasoning test such that questions only require very basic knowledge (such as arithmetic) and responding rests on reasoning abilities for novel problems. We utilized two types of YGS scores, one with higher weight on quantitative reasoning (YGS1) and one with higher weight on verbal 
reasoning (YGS3). YGS1 comprises 40\% numeric, 30\% science, and 30\% Turkish verbal comprehension questions, whereas YGS3 comprises 20\% numeric, $10 \%$ science, and $70 \%$ Turkish verbal comprehension questions (ÖSYM, 2014). The LYS test is a content-based test such that responding to questions requires relatively more advanced knowledge in different content domains such as mathematics, physics, history and so on. Depending on the major area the student is going for, different university admission tests are taken yielding different composite scores such as a Social-Math score or a Math-Science score. In the analyses, the MS score, which includes mathematics, geometry, physics, chemistry, and biology content domains, was used as the LYS score for the STEM cluster (LYS-MS). The SocM score, which includes mathematics, geometry, Turkish language and literature, and geography content domains, was utilized as the LYS score for the social and administrative sciences cluster (LYS-SocM). Participants also reported their cumulative GPA (CGPA) scores. For those participants who did not report their CGPAs, the latest CGPA was obtained from the university student information system with the students' consent.

Table 1. Demographic characteristics of the sample

\begin{tabular}{lrr}
\hline $\mathbf{N}=\mathbf{4 4 1})$ & STEM & $\begin{array}{c}\text { Social Sciences/ } \\
\text { Humanities }\end{array}$ \\
\hline Gender N (\%) & $85(36.8)$ & $141(67.1 .0)$ \\
Women & $146(63.2)$ & $68(32.4)$ \\
Men & & \\
Departmental domain N (\%) & $176(76.2)$ & \\
Engineering & $55(23.8)$ & $65(31.0)$ \\
Physical sciences & & $145(69.0)$ \\
Administrative sciences (Business/Economics) & & \\
Social sciences/Humanities & & \\
\hline
\end{tabular}

The 9-item GRIT scale by Duckworth and Quinn (2009) was utilized for measuring students' determination and passion for long-term goals, which was translated and backtranslated by two bilinguals for the present study. The scale has two dimensions, namely perseverance of effort and consistency of interest. Sample items are "I finish whatever I begin" (perseverance of effort) and "I often set a goal but later choose to pursue a different one" (consistency of interest, reverse-coded). 


\section{Results}

\subsection{STEM cluster}

Descriptive statistics and variable inter-correlations for the STEM cluster are presented in Table 2. In this cluster, CGPA had small correlations with the reasoning test of YGS1 ( $r=$ $.17, p<.001)$, and the content test of MS $(r=.22, p<.001)$. Grit-perseverance of effort had a moderate significant correlation with CGPA $(r=.30, p<.001)$.

Table 2. Descriptive statistics and inter-correlations of the study variables for the STEM cluster

\begin{tabular}{lrrllll}
\hline & Mean & SD & $\begin{array}{l}\text { Reasoning } \\
\text { Test }- \text { Quant } \\
\text { (YGS1) }\end{array}$ & $\begin{array}{l}\text { Content } \\
\text { test } \\
\text { (LYS-MS) }\end{array}$ & $\begin{array}{l}\text { Grit } \\
\text { Effort }\end{array}$ & $\begin{array}{l}\text { Grit } \\
\text { Interest }\end{array}$ \\
\hline CGPA & 2.79 & .59 & $.17^{* *}$ & $.22^{* *}$ & $.30^{* *}$ & $.17^{* * *}$ \\
$\begin{array}{l}\text { Reasoning Test }- \\
\text { Quant (YGS1) }\end{array}$ & 434.59 & 37.32 & & $.78^{* *}$ & -.02 & .01 \\
Content test (MS) & 435.62 & 44.61 & & & .08 & -.04 \\
Grit Effort & 4.03 & .91 & & .78 & $.40^{* *}$ \\
Grit Interest & 3.29 & .80 & & & $\mathbf{. 6 1}$ \\
\hline
\end{tabular}

$\mathrm{N}=231$. Bold fonts are Cronbach's alpha coefficients. Quant: $70 \%$ of test coverage is quantitative.

$* p<.05, * * p<.01$.

The content LYS-MS scores alone added $2 \%$ of incremental variance over the reasoning YGS1 test in predicting CGPA $\left(F_{\text {change }}(1,228)=4.39, p=.04\right)$. When MS scores were included in the first step, it explained 5\% variance and YGS scores did not explain a significant amount of incremental variance over MS scores $\left(F_{\text {change }}(1,228)=.001, p=.97\right)$. When the grit dimensions were added in the final step, they together explained an additional $9 \%$ variance over the reasoning and content test scores. When all variables were included in the regression, they explained $13.6 \%$ variance in CGPA and grit-perseverance of effort was the only significant predictor $(\beta=.26, p<.001)$. Relative importance of test types and grit (perseverance of effort) on academic achievement was studied with the dominance analysis approach (Azen \& Budescu, 2003; Budescu, 1993). Dominance analysis was preferred over a one-shot regression analysis in order to take account of variable inter-correlations, as the MS and YGS1 test scores are highly correlated $(r=.78)$. The reasoning test of YGS shared $2 \%$ of variance with CGPA, the content test of MS shared $3 \%$ of variance with CGPA, and finally perseverance of effort shared $9 \%$ of variance with CGPA. Variables' contributions to the shared variance were $12 \%$ for the reasoning test, $22 \%$ for the content test, and $67 \%$ for grit. The hypothesis, which stated that the 
content test indicative of a knowledge-based assessment would have a larger relative contribution to the prediction of CGPA as compared to a reasoning test, was supported.

\subsection{Social-administrative sciences cluster}

Descriptive statistics and variable inter-correlations for the social-administrative sciences cluster are presented in Table 3. In this cluster, CGPA had a nonsignificant correlation with the reasoning test of YGS1 $(r=.08, p=.27)$ and small significant correlations with YGS3 $(r=.14, p=.04)$ and the content test of LYS-SocM $(r=.15, p=.03)$. Grit-perseverance of effort had a greater significant correlation with CGPA $(r=.25, p<.001)$.

Table 3. Descriptive statistics and intercorrelations of the study variables for the social/administrative sciences cluster

\begin{tabular}{|c|c|c|c|c|c|c|c|}
\hline & Mean & SD & YGS1 & YGS3 & $\begin{array}{l}\text { LYS- } \\
\text { SocM }\end{array}$ & $\begin{array}{l}\text { Grit } \\
\text { Effort }\end{array}$ & $\begin{array}{l}\text { Grit } \\
\text { Interest }\end{array}$ \\
\hline CGPA & 2.78 & .68 & .08 & $.14 *$ & $.15^{*}$ & $.25^{* *}$ & $.16^{*}$ \\
\hline $\begin{array}{l}\text { Reasoning Test - } \\
\text { Quant (YGS1) }\end{array}$ & 350.68 & 49.68 & & $.67 * *$ & $.50 * *$ & -.06 & .00 \\
\hline $\begin{array}{l}\text { Reasoning Test - } \\
\text { Verbal (YGS3) }\end{array}$ & 395.04 & 30.26 & & & $.55^{* *}$ & .05 & .12 \\
\hline $\begin{array}{ll}\text { Content } & \text { test } \\
(\text { LYS-SocM) } & \end{array}$ & 391.52 & 41.61 & & & & .05 & .00 \\
\hline Grit Effort & 3.86 & .83 & & & & .72 & $.44 * *$ \\
\hline Grit Interest & 3.16 & .80 & & & & & .65 \\
\hline
\end{tabular}

$\overline{\mathrm{N}}=210$. Bold fonts are Cronbach's alpha coefficients. Quant: 70\% of test coverage is quantitative; Verbal: 70\% of test coverage is verbal. $* p<.05,{ }^{* *} p<.01$.

In the social-administrative sciences cluster CGPA was more strongly correlated with YGS3, which rests on reasoning with verbal content, than YGS1 which measures reasoning with quantitative content. However, since YGS3 test has a higher load of knowledge content based on the test manual, it is not suitable for testing our hypothesis, which compares Gf and Gc measures. Therefore, for dominance analysis we utilized YGS1 scores as the reasoning test score. For space purposes, the dominance analysis results for YGS3 are not presented here and are available upon request. YGS1 shared less than $1 \%$ variance with CGPA, the content test SocM shared 2\% variance with CGPA, and grit (perseverance of effort) shared $6 \%$ of variance with CGPA. Variables' contributions to the explained variance in CGPA were $5 \%$ for the reasoning test, $20 \%$ for the content test, and $75 \%$ for 
grit. The relative contribution of the knowledge-based test score was four 4 times than that of the reasoning test score. Again, perseverance of effort was the best predictor of academic success.

\section{Discussion}

Using data collected from both STEM and social sciences students, we found support for our hypotheses that college success is better predicted by Gc than Gf measures. Specifically, for both samples, the knowledge-based test explained greater variance in CGPA than the reasoning test. Our findings offer further contribution to the literature, which reported that intelligence-as-knowledge measures are better predictors of academic success than intelligence-as-process measures (e.g., McManus et al., 2011; Postlethwaite, 2011). We also provide further support to Ackerman's PPIK theory and Cattell's Investment theory. It is also important to note that perseverance of effort dimension of the grit scale performed as the best predictor among all variables in both samples. This finding is in line with the previous studies which found that grit explained incremental variance over IQ scores (e.g., Duckworth et al., 2007) and that non-cognitive variables are important in investing ability-related resources in effortful pursuits (Ackerman, 1996).

Our study is not without its limitations. Our findings are not conclusive for the Turkish exam system because of the limited sample sizes and participant profile. It should be noted that the data collection is ongoing and the results reported here are preliminary. When the sample size is enlarged with sufficient representation of various majors, multilevel methods can be utilized to test the relative contributions of crystalized and fluid intelligence on academic success for students from different domains.

\section{References}

Ackerman, P. L. (1996). A theory of adult intellectual development: Process, personality, interests, and knowledge. Intelligence, 22, 227-257.

Ackerman, P. L., \& Beier, M. E. (2006). Determinants of domain knowledge and independent study learning in an adult sample. Journal of Educational Psychology, 98(2), 366-381.

Ackerman, P. L., Kanfer, R., \& Calderwood, C. (2013). High school Advanced Placement and student performance in college: STEM majors, non-STEM majors, and gender differences. Teachers College Record, 115(10), 1-43.

Azen, R., \& Budescu, D. V. (2003). The dominance analysis approach for comparing predictors in multiple regression. Psychological Methods, 8(2), 129-148. 
Budescu,D. V. (1993). Dominance analysis: A new approach to the problem of relative importance of predictors in multiple regression. Psychological Bulletin, 114(3), 542551.

Cattell, R.B. (1987). Intelligence: Its Structure, Growth, and Action. New York: NorthHolland.

Cliffordson, C. (2008). Differential prediction of study success across academic programs in the Swedish context: The validity of grades and tests as selection instruments for higher education. Educational Assessment, 13(1), 56-75.

Duckworth, A. L., Peterson, C., Matthews, M. D., \& Kelly, D. R. (2007). Grit: perseverance and passion for long-term goals. Journal of Personality and Social Psychology, 92(6), 1087-1101.

Duckworth, A. L., \& Quinn, P. D. (2009). Development and validation of the Short Grit Scale (GRIT-S). Journal of Personality Assessment, 91(2), 166-174.

Fu, Y. (2012). The Effectiveness of Traditional Admissions Criteria in Predicting College and Graduate Success for American and International Students. ProQuest LLC, Ph.D. Dissertation, The University of Arizona.

Geiser, S., \& Studley, W. R. (2002). UC and the SAT: Predictive validity and differential impact of the SAT I and SAT II at the University of California. Educational Assessment, 8(1), 1-26.

Kaufman, A. S., Johnson, C. K., \& Liu, X. (2008). A CHC theory-based analysis of age differences on cognitive abilities and academic skills at ages 22 to 90 years. Journal of Psychoeducational Assessment, 26, 350-381.

Kilmen, S. (2007). Lisansüstü eğitimi giriş sınavının ve lisans diploma notunun yüksek lisans başarısını yordama gücü. Abant İzzet Baysal Üniversitesi Eğitim Fakültesi Dergisi, 7(2), 176-189.

Koczwara, A., Patterson, F., Zibarras, L., Kerrin, M., Irish, B., \& Wilkinson, M. (2012). Evaluating cognitive ability, knowledge tests and situational judgement tests for postgraduate selection. Medical Education, 46(4), 399-408.

Kuncel, N. R., \& Hezlett, S. A. (2007). Standardized tests predict graduate students' success. Science, 315 (5815), 1080-1081.

Kuncel, N. R., Hezlett, S. A., \& Ones, D. S. (2001). A comprehensive meta-analysis of the predictive validity of the graduate record examinations: implications for graduate student selection and performance. Psychological Bulletin, 127(1), 162-181.

Kunina, O., Wilhelm, O., Formazin, M., Jonkmann, K., \& Schroeders, U. (2007). Extended criteria and predictors in college admission: Exploring the structure of study success and investigating the validity of domain knowledge. Psychology Science, 49(2), 88-114.

Lin, P., \& Humphreys, L. (1977). Predictions of academic performance in graduate and professional school. Applied Psychological Measurement, 1(2), 249-257.

McManus, I. C., Ferguson, E., Wakeford, R., Powis, D., \& James, D. (2011). Predictive validity of the Biomedical Admissions Test: an evaluation and case study. Medical Teacher, 33(1), 53-57. 
ÖSYM. (2014). 2014 Öğrenci Seçme Ve Yerleştirme Sistemi (ÖSYS) Kılavuzu. Retrieved from http://dokuman.osym.gov.tr/pdfdokuman/2014/YGS/2014_OSYS_KILAVUZU_ 02_01_2014.pdf.

Ouellette, J. A., \& Wood, W. (1998). Habit and intention in everyday life: the multiple processes by which past behavior predicts future behavior. Psychological Bulletin, 124(1), 54.

Postlethwaite, B. E. (2011). Fluid ability, crystallized ability, and performance across multiple domains: a meta-analysis (Doctoral dissertation). Retrieved from Iowa Research Online.

Richardson, M., Abraham, C., \& Bond, R. (2012). Psychological correlates of university students' academic performance: A systematic review and meta-analysis. Psychological Bulletin, 138, 353-387.

Rolfhus, E. L., \& Ackerman, P. L. (1999). Assessing individual differences in knowledge: Knowledge, intelligence, and related traits. Journal of Educational Psychology, 91(3), 511-526.

Sackett, P. R., Borneman, M. J., \& Connelly, B. S. (2008). High-stakes testing in higher education and employment: Appraising the evidence for validity and fairness. American Psychologist, 63, 215-227. 